\title{
Expression and penetrance of the hereditary pancreatitis phenotype in monozygotic twins
}

\author{
S T Amann, L K Gates, C E Aston, A Pandya, D C Whitcomb
}

Department of Medicine, Division of Gastroenterology, Hepatology, and Nutrition, University of Florida, Gainesville, FL 32610-0214, USA

S T Amann

University of Kentucky Medical Center, Lexington, KY 40536, USA

L K Gates

Center for Genomic Sciences, University of Pittsburgh, Pittsburgh, PA 15261, USA

C E Aston

D C Whitcomb

Department of Human Genetics, University of Pittsburgh, Pittsburgh, PA 15261, USA

C E Aston

Department of Medicine, University of Pittsburgh, Pittsburgh, PA 15261, USA

D C Whitcomb

Department of Cell Biology and Physiology, University of Pittsburgh, Pittsburgh, PA 15261, USA

D C Whitcomb

Department of Human Genetics, Medical College of Virginia at Virginia

Commonwealth University, Richmond, VA 23298, USA

A Pandya

VA Pittsburgh Health Care System, Pittsburgh, PA 15240, USA

D C Whitcomb

Correspondence to: Dr S T Amann, Director of Pancreatic Services and Therapeutic Endoscopy, North Mississippi Medical Center, PO Box 21, Tupelo, MS 38802, USA. samann@NMHS.net

Accepted for publication 2 August 2000
Abstract

Background-Hereditary pancreatitis (HP) is a rare autosomal dominant disorder with variable expression and an overall lifetime penetrance of $80 \%$. We hypothesised that (1) monozygotic twins within similar environments would develop the typical signs of $H P$ at a similar age, and (2) if penetrance were due to modifier genes or environment, all twin pairs would be concordant for expression of HP.

Aim-Identify monozygotic twins with HP and determine the penetrance, concordance, and age of onset of symptoms.

Methods-Twins from HP kindreds were identified from the Midwest Multicenter Pancreatic Study group database, referrals, and literature searches. Each twin set was assessed for phenotypic expression, concordance, and difference in age of phenotypic onset of pancreatitis. The difference in onset of symptoms for symptomatic affected non-twin sibling pairs as well as non-twin pairs that were mutation, sex, and age matched were calculated as two comparison groups.

Results-Seven of 11 monozygotic pairs identified were suitable for evaluation and four were concordant for pancreatitis. Forty eight affected sibling pairs and 33 pairs of mutation, sex, and age matched (cationic trypsinogen $\mathrm{R} 122 \mathrm{H}$ (30 pairs) and N29I (three pairs)) subjects were identified for comparison groups. The median (quartiles Q1, Q3) difference in the age of phenotypic onset in the concordant twins was $1(0,2.4)$ years, $2(1,6)$ for the affected siblings, and $7(2,15)$ years in the comparison control group. Three of the seven sets of twins (43\%) were discordant for phenotypic expression of pancreatitis. The overall penetrance in the seven pairs of monozygotic twins was $78.6 \%$.

Conclusions-Genetic and/or environmental factors contribute to expression and age of onset of HP. Nuclear genes or general environmental factors alone cannot explain the $80 \%$ penetrance. Determining the mechanism of non-penetrance may help in developing a strategy to prevent the phenotypic expression of pancreatitis in individuals with an underlying genetic predisposition.

(Gut 2001;48:542-547)

Keywords: hereditary pancreatitis; genetic; twins; penetrance; trypsinogen
Hereditary pancreatitis (HP) is a rare autosomal dominant disorder with $80 \%$ penetrance, variable expression, and onset usually occurring during childhood but ranging from birth to the fifth or sixth decade of life. ${ }^{1-3}$ Three mutations in the cationic trypsinogen gene on chromosome 7 have been identified that clearly predispose patients to acute and chronic pancreatitis. The cationic trypsin mutations, now reported according to the Working Group recommendations ${ }^{4}$ rather than the chymotrypsinogen numbering system (chy\#), ${ }^{5}$ include R122H (chy\# R117H ${ }^{6}$ ), N29I (chy\# $\mathrm{N} 21 \mathrm{I}^{7}$ ), and A16V. ${ }^{8}$ These mutations account for the majority of cases although other genetic mutations are also likely. ${ }^{9}{ }^{10}$ The trypsinogen mutations are thought to impede autolysis of inappropriately activated trypsinogen within the pancreas, or enhance trypsinogen activation, resulting in activation of the digestion enzyme cascade, acinar cell autodigestion, and subsequent pancreatitis. ${ }^{6}$

$\mathrm{HP}$ is not a fully penetrant disease; that is, not all individuals who inherit the dominant mutant allele develop clinically recognisable symptoms. Surprisingly, a review of large kindreds worldwide revealed that this disorder has a consistent rate of penetrance of $80 \%$ across all populations. ${ }^{23^{11-13}}$ The aetiological mechanism for this incomplete penetrance is unknown but may involve genetic factors such as effects of modifier genes or imprinting, or avoidance of environmental factors such as viral infection, trauma, or oxidative stress. ${ }^{14-17}$ Separating potential genetic factors from environmental causes remains a formidable task. However, genetic variables can be controlled to a large degree through the study of monozygotic twins who share all their nuclear genes, including potential expression modifiers. Environmental factors are also controlled due to a common environment.

We hypothesised that if penetrance were due to modifier genes or environment, monozygotic twins reared together sharing similar environments, (i) would be concordant for phenotypic expression of HP, and (ii) would develop the typical signs of $\mathrm{HP}$ at a similar age.

In the current study, monozygotic twin pairs were evaluated for concordance of phenotypic expression to determine the penetrance of HP. The difference in age of onset of pancreatitis among the concordant twin pairs was compared with two groups. The first group was affected sibling pairs and a second group of unrelated affected individuals matched pairwise for trypsinogen gene mutation, sex, and current age as the control group. This offers the

Abbreviations used in this paper: HP, hereditary pancreatitis. 
ability to evaluate the effects of genetic and environmental factors on penetrance and expression of HP. The group of affected siblings would be expected to have similar environments and approximately half of the modifying genes. The unrelated matched control group would likely differ in both genetic and environmental influences to a greater degree. Differences in the age of disease onset in these groups, compared with the twins, would suggest that environmental factors or modifying genes may be important in disease expression.

\section{Material and methods}

SUBJECT IDENTIFICATION

Two sets of identical twins with HP were identified by our group during previous studies. ${ }^{67} \mathrm{~A}$ search of the database and pedigrees from the Midwest Multicenter Pancreatic Study Group was conducted to ascertain further twin pairs. In addition, all kindreds in published reports on HP were reviewed and investigators caring for large kindreds were queried for other twin sets. Phenotypic expression and age of disease onset were determined for the twins. HP was defined as noted previously. ${ }^{2} 6$

\section{PHENOTYPIC CHARACTERISATION}

Clinical information was obtained from subjects, family members, or medical record review, as appropriate. Criteria for confirmation of the phenotypic expression for pancreatitis within a HP kindred were: (1) elevated amylase or lipase levels with abdominal pain consistent with acute pancreatitis; (2) radiographic (endoscopic retrograde cholangiopancreatography, computed tomography, or calcifications on abdominal film) or surgical evidence (biopsy proved fibrosis and/or treatment of chronic pancreatitis) of pancreatitis; or (3) a clear clinical history of repeated episodes of characteristic abdominal pain beginning in childhood. $^{2} 3121317$ Genetic analysis of known mutations in trypsinogen $(\mathrm{R} 122 \mathrm{H}, \mathrm{N} 29 \mathrm{I}$, and A16V) were used to confirm genotype where possible. In the absence of genetic studies, inclusion required that the twins developed the phenotypic hallmarks of HP without other identifiable causes before age 20 or had offspring or relatives in multiple generations affected with pancreatitis. Non-penetrance of disease manifestation or phenotype was confirmed by lack of clinical symptoms and/or history consistent with pancreatic disease.

\section{CONFIRMATION OF ZYGOSITY}

To determine whether phenotypically discordant twins were monozygotic, we used highly informative microsatellite markers from the ABI Prism Linkage Mapping Set (Perkin Elmer Applied Biosystems, Foster City, Callifornia, USA) located on eight or more chromosomes for amplification and haplotyping using previously described methods. ${ }^{17}$ The markers for each twin pair were compared to confirm the zygosity assignment. The probability of monozygosity for twin pairs who are identical for more than five highly polymorphic markers is greater than $99.9 \%$. Monozygosity was confirmed in two of the three discordant twin sets.

\section{MUTATION ANALYSIS}

Genomic DNA was extracted using the Gentra Systems Puregene DNA purification protocol (Research Triangle Park, North Carolina, USA). Exon 3 of the human cationic trypsinogen gene was amplified using a nested PCR strategy. ${ }^{6}$ Initial screening for the trypsinogen $\mathrm{R} 122 \mathrm{H}$ mutation was done using the AfIIII (New England Biolabs) restriction enzyme digestion as previously described. ${ }^{6}$ A positive result for the $G$ to $A$ mutation was confirmed by sequencing. The $\mathrm{T}$ to A mutation (N29I) was determined by direct sequencing of exon 2 using the ABI Prism dRhodamine Terminator Cycle Sequencing Ready Reaction Kit (PE Applied Biosystems Division of Perkin-Elmer) according to the manufacturer's recommendations, as previously described. ${ }^{67}$

Primer sets for exon 2 were: (forward) TGTGAGGACATTCCTTGCGA and CGCCACCCCTAACATGCTATTG; and (reverse) TCT TCCTGAAAATTTTGACT and CCATCTTACCCAACCTCAGTAG. Primer sets for exon 3 were: (forward) GGTCCTGGGTCTCATACCTT and TGACCCACATCCCTC TGCTG; and (reverse) GGGTAGGAGGCTTCACACTT and TCTCCATTTGTCCTGTCTCT.

Age of disease onset: affected sibling pairs

Forty eight sibling pairs were identified from the database. They were grouped by mutation (R122H, N29I, other), and difference in age of phenotype onset was determined.

Age of disease onset: control group

Individuals from the 74 kindreds with phenotypic expression of pancreatic disease were pooled and then categorised by cationic trypsinogen gene mutation $\mathrm{R} 122 \mathrm{H}$ or N29I. Individuals with a clear family history but without identifiable mutations were excluded because it was not possible to match them with another person of similar genetic predisposition. Within each of these gene mutation groups, patients were ranked by sex and present age. Individuals with a similar age (within four years) were then paired for further analysis. Since these individuals came from many kindreds, they were not necessarily related. Individuals who were unique for their mutation-gender-age combination and could not be paired were excluded. For each pair, the difference in age of onset of pancreatitis was calculated.

\section{STATISTICS}

The difference in age of onset of pancreatitis was compared between groups using the Mann-Whitney U test; $p<0.05$ was considered statistically significant.

\section{Results}

IDENTIFICATION OF MONOZYGOTIC TWINS

Eleven pairs of monozygotic twins with HP were identified from all sources. ${ }^{26717-20}$ Four twin pairs were excluded from analysis. The twins reported by Henderson and colleagues ${ }^{20}$ 
Table 1 Demographics, phenotype, and genotype of monozygotic twin sets

\begin{tabular}{|c|c|c|c|c|c|c|c|}
\hline $\begin{array}{l}\text { Twin } \\
\text { group }\end{array}$ & Age (y) & Sex & Mutation & Age of onset $(y)$ & $\begin{array}{l}\text { Difference in age } \\
\text { of onset }(y)\end{array}$ & Ref. No & Note \\
\hline $\mathrm{A} 1$ & 41 & $\mathrm{~F}$ & $\mathrm{R} 122 \mathrm{H}$ & 5 & & & \\
\hline A2 & 41 & $\mathrm{~F}$ & $\mathrm{R} 122 \mathrm{H}$ & No & $>36$ & 6 & Discordant \\
\hline G1 & 36 & $\mathrm{~F}$ & N29I & 13 & & & \\
\hline G2 & 36 & $\mathrm{~F}$ & N29I & No & $>23$ & 7 & Discordant \\
\hline $\mathrm{T} 1$ & 24 & $\mathrm{~F}$ & $\mathrm{R} 122 \mathrm{H}$ & 16 & & & \\
\hline $\mathrm{T} 2$ & 24 & $\mathrm{~F}$ & $\mathrm{R} 122 \mathrm{H}$ & 14 & 2 & & \\
\hline B1 & 8 & $\mathrm{~F}$ & UNK & $3-5$ & & & \\
\hline B2 & 8 & $\mathrm{~F}$ & UNK & $3-5$ & 0 & & \\
\hline V1 & $\mathrm{D}$ & M & $\mathrm{R} 122 \mathrm{H}$ & Childhood & & & \\
\hline V2 & $\mathrm{D}$ & M & R122H & No & & 21 & Discordant \\
\hline C1 & 63 & $\mathrm{~F}$ & UNK & 40 & & & \\
\hline $\mathrm{C} 2$ & 63 & $\mathrm{~F}$ & UNK & $\sim 40$ & $3-4$ & & PC \\
\hline $\mathrm{F} 1$ & 17 & $\mathrm{~F}$ & NT & Infant & & & \\
\hline $\mathrm{F} 2$ & 17 & $\mathrm{~F}$ & NT & Infant & 0 & 19 & \\
\hline
\end{tabular}

D, deceased; UNK, unknown gene; NT, not tested; PC, pancreatic cancer.

and Beall and colleagues ${ }^{18}$ were concordant in phenotype but were excluded because of the late age of disease onset (34 years and 31 years) in the context of excessive alcohol consumption. A pair of 13 year old twins from the J family, ${ }^{10}$ and a pair of six year old twins of the $\mathrm{P}$ family ${ }^{21}$ each have an affected father but were excluded from the study because of undetermined genotype and because the twins were less than 20 years of age and without phenotypic expression of pancreatitis.

Table 2 Affected sibling pairs from hereditary pancreatitis kindreds

\begin{tabular}{|c|c|c|c|}
\hline $\begin{array}{l}\text { Trypsin } \\
\text { mutation }\end{array}$ & $\begin{array}{l}\text { Type of } \\
\text { relationship }\end{array}$ & $\begin{array}{l}\text { Age of onset of } \\
\text { phenotype (y) }\end{array}$ & $\begin{array}{l}\text { Difference in age } \\
\text { of onset (y) }\end{array}$ \\
\hline$+\mathrm{R} 122 \mathrm{H}$ & $S$ & 2,3 & 1 \\
\hline$+\mathrm{R} 122 \mathrm{H}$ & S & 2,3 & 1 \\
\hline$+\mathrm{R} 122 \mathrm{H}$ & $\mathrm{S}$ & 3,3 & 0 \\
\hline$+\mathrm{R} 122 \mathrm{H}$ & $\mathrm{S}$ & 2,3 & 1 \\
\hline$+\mathrm{N} 29 \mathrm{I}$ & $\mathrm{S}$ & 9,6 & 3 \\
\hline Other & S & 4,6 & 2 \\
\hline$+\mathrm{N} 29 \mathrm{I}$ & S & 28,40 & 12 \\
\hline$+\mathrm{R} 122 \mathrm{H}$ & S & 18,21 & 3 \\
\hline$+\mathrm{R} 122 \mathrm{H}$ & $\mathrm{S}$ & 21,19 & 2 \\
\hline$+\mathrm{R} 122 \mathrm{H}$ & S & 18,19 & 1 \\
\hline$+\mathrm{R} 122 \mathrm{H}$ & $\mathrm{S}$ & 13,13 & 0 \\
\hline Other & S & 12,9 & 3 \\
\hline Other & S & 2,4 & 2 \\
\hline$+\mathrm{R} 122 \mathrm{H}$ & $\mathrm{S}$ & 18,15 & 3 \\
\hline Other & $\mathrm{S}$ & 6,8 & 2 \\
\hline$+\mathrm{R} 122 \mathrm{H}$ & $\mathrm{S}$ & 15,14 & 1 \\
\hline + Other & S & 20,20 & 0 \\
\hline$+\mathrm{R} 122 \mathrm{H}$ & $\mathrm{S}$ & 3,7 & 4 \\
\hline$+\mathrm{R} 122 \mathrm{H}$ & $\mathrm{S}$ & 7,5 & 2 \\
\hline$+\mathrm{R} 122 \mathrm{H}$ & $\mathrm{S}$ & 3,5 & 2 \\
\hline$+\mathrm{R} 122 \mathrm{H}$ & $\mathrm{S}$ & 5,11 & 6 \\
\hline$+\mathrm{R} 122 \mathrm{H}$ & $\mathrm{S}$ & 16,11 & 5 \\
\hline$+\mathrm{R} 122 \mathrm{H}$ & B & 26,20 & 6 \\
\hline+ Other & B & 22,19 & 3 \\
\hline+ Other & B & 20,20 & 0 \\
\hline+ Other & B & 19,15 & 4 \\
\hline$+\mathrm{R} 122 \mathrm{H}$ & $\mathrm{B}$ & 11,3 & 8 \\
\hline$+\mathrm{R} 122 \mathrm{H}$ & $\mathrm{S} / \mathrm{B}$ & 2,1 & 1 \\
\hline$+\mathrm{R} 122 \mathrm{H}$ & $\mathrm{S} / \mathrm{B}$ & 3,1 & 2 \\
\hline$+\mathrm{R} 122 \mathrm{H}$ & $\mathrm{S} / \mathrm{B}$ & 3,1 & 2 \\
\hline$+\mathrm{R} 122 \mathrm{H}$ & S/B & 38,17 & 21 \\
\hline$+\mathrm{R} 122 \mathrm{H}$ & $\mathrm{S} / \mathrm{B}$ & 12,10 & 2 \\
\hline+ Other & S/B & 13,14 & 1 \\
\hline + Other & S/B & 2,2 & 0 \\
\hline$+\mathrm{R} 122 \mathrm{H}$ & $\mathrm{S} / \mathrm{B}$ & 10,11 & 1 \\
\hline$+\mathrm{N} 29 \mathrm{I}$ & S/B & 2,12 & 10 \\
\hline$+\mathrm{R} 122 \mathrm{H}$ & $\mathrm{S} / \mathrm{B}$ & 35,6 & 29 \\
\hline + Other & $\mathrm{S} / \mathrm{B}$ & 18,21 & 3 \\
\hline$+\mathrm{R} 122 \mathrm{H}$ & $\mathrm{S} / \mathrm{B}$ & 3,4 & 1 \\
\hline$+\mathrm{R} 122 \mathrm{H}$ & $\mathrm{S} / \mathrm{B}$ & 2,39 & 37 \\
\hline$+\mathrm{N} 29 \mathrm{I}$ & $\mathrm{S} / \mathrm{B}$ & 3,4 & 1 \\
\hline$+\mathrm{R} 122 \mathrm{H}$ & $\mathrm{S} / \mathrm{B}$ & 3,3 & 0 \\
\hline+ Other & S/B & 24,40 & 16 \\
\hline$+\mathrm{R} 122 \mathrm{H}$ & $\mathrm{S} / \mathrm{B}$ & 3,32 & 30 \\
\hline$+\mathrm{R} 122 \mathrm{H}$ & $\mathrm{S} / \mathrm{B}$ & 7,32 & 25 \\
\hline$+\mathrm{R} 122 \mathrm{H}$ & S/B & 5,32 & 27 \\
\hline$+\mathrm{R} 122 \mathrm{H}$ & $\mathrm{S} / \mathrm{B}$ & 1,10 & 9 \\
\hline$+\mathrm{R} 122 \mathrm{H}$ & S/B & 9,13 & 4 \\
\hline
\end{tabular}

$\mathrm{S}$, sisters; $\mathrm{B}$, brothers; $\mathrm{S} / \mathrm{B}$, sister and brother.
Seven sets of twins were analysed (table 1). Of the three twin pairs with a cationic trypsinogen $\mathrm{R} 122 \mathrm{H}$ mutation, two pairs $(\mathrm{A}, \mathrm{V})$ were discordant for pancreatitis with the age of onset for the affected twin of five years (A) and early childhood (V2). One twin pair (G) had the cationic trypsinogen N29I mutation and was discordant for pancreatitis and the affected twin developed pancreatitis at age 13. Three twin pairs had none of the known trypsinogen mutations, and they were all concordant for pancreatitis. Although a trypsinogen mutation was not identified, these families met criteria for an affected kindred and are likely one of the unidentified mutations. Review of available information suggested an autosomal dominant inheritance pattern. This included a pair of eight year old girls from kindred B, both of whom had onset of pancreatitis between the ages of three and five, and a pair of 63 year old twins from kindred $\mathrm{C}$, with late onset of pancreatitis at age 40 . The twins reported by Freud and colleagues ${ }^{19}$ were Israeli girls of Ashkenazi origin (kindred F) who both developed pancreatitis in infancy that progressed to chronic pancreatitis.

DIFFERENCES IN AGE OF ONSET AMONG TWINS AND INDIVIDUALS WITH HEREDITARY PANCREATITIS

Four of the 11 twin pairs that were concordant for phenotype (kindreds T, B, C, and F) were analysed for difference in age of disease onset. The median (quartile (Q)1, Q3) and mean (SD) intervals between the age of disease onset were $1(0,2.4)$ and $1.5(1.0)$ years, respectively.

The affected sibling group included 48 pairs; five were brothers, 22 were sisters, and 21 were sister-brother (table 2). The median (Q1, Q3)

Table 3 Pairs of mutation, sex, and age matched controls from hereditary pancreatitis kindreds

\begin{tabular}{|c|c|c|c|c|}
\hline $\begin{array}{l}\text { Trypsin } \\
\text { mutation }\end{array}$ & Sex & $\begin{array}{l}\text { Current } \\
\text { age }(y)\end{array}$ & $\begin{array}{l}\text { Age of onset of } \\
\text { phenotype }(y)\end{array}$ & $\begin{array}{l}\text { Difference in } \\
\text { age of onset }(y)\end{array}$ \\
\hline$+\mathrm{R} 122 \mathrm{H}$ & $\mathrm{F}$ & 13,13 & 4,10 & 6 \\
\hline$+\mathrm{R} 122 \mathrm{H}$ & $\mathrm{F}$ & 18,19 & 13,13 & 0 \\
\hline$+\mathrm{R} 122 \mathrm{H}$ & $\mathrm{F}$ & 20,23 & 5,7 & 2 \\
\hline$+\mathrm{R} 122 \mathrm{H}$ & $\mathrm{F}$ & 29,29 & 5,20 & 15 \\
\hline$+\mathrm{R} 122 \mathrm{H}$ & $\mathrm{F}$ & 32,33 & 11,3 & 8 \\
\hline$+\mathrm{R} 122 \mathrm{H}$ & $\mathrm{F}$ & 35,35 & 1,5 & 4 \\
\hline$+\mathrm{R} 122 \mathrm{H}$ & $\mathrm{F}$ & 35,35 & 5,7 & 2 \\
\hline$+\mathrm{R} 122 \mathrm{H}$ & $\mathrm{F}$ & 38,38 & 34,34 & 0 \\
\hline$+\mathrm{R} 122 \mathrm{H}$ & $\mathrm{F}$ & 40,40 & 10,38 & 28 \\
\hline$+\mathrm{R} 122 \mathrm{H}$ & $\mathrm{F}$ & 44,46 & 16,12 & 4 \\
\hline$+\mathrm{R} 122 \mathrm{H}$ & $\mathrm{F}$ & 49,52 & 11,6 & 5 \\
\hline$+\mathrm{R} 122 \mathrm{H}$ & $\mathrm{F}$ & 62,64 & 18,53 & 35 \\
\hline$+\mathrm{R} 122 \mathrm{H}$ & $\mathrm{F}$ & 71,73 & 3,10 & 7 \\
\hline$+\mathrm{R} 122 \mathrm{H}$ & $\mathrm{F}$ & 75,75 & 72,2 & 70 \\
\hline$+\mathrm{R} 122 \mathrm{H}$ & $M$ & 4,4 & 1,3 & 2 \\
\hline$+\mathrm{R} 122 \mathrm{H}$ & M & 7,8 & 2,1 & 1 \\
\hline$+\mathrm{R} 122 \mathrm{H}$ & M & 14,14 & 3,12 & 9 \\
\hline$+\mathrm{R} 122 \mathrm{H}$ & M & 16,16 & 1,5 & 4 \\
\hline$+\mathrm{R} 122 \mathrm{H}$ & M & 19,22 & 12,13 & 1 \\
\hline$+\mathrm{R} 122 \mathrm{H}$ & M & 25,27 & 5,5 & 0 \\
\hline$+\mathrm{R} 122 \mathrm{H}$ & $M$ & 28,29 & 0,2 & 2 \\
\hline$+\mathrm{R} 122 \mathrm{H}$ & $M$ & 30,32 & 19,6 & 13 \\
\hline$+\mathrm{R} 122 \mathrm{H}$ & M & 33,33 & 4,14 & 10 \\
\hline$+\mathrm{R} 122 \mathrm{H}$ & M & 35,36 & 26,6 & 20 \\
\hline$+\mathrm{R} 122 \mathrm{H}$ & M & 40,41 & 0,13 & 13 \\
\hline$+\mathrm{R} 122 \mathrm{H}$ & M & 45,45 & 12,17 & 5 \\
\hline$+\mathrm{R} 122 \mathrm{H}$ & M & 47,47 & 16,20 & 4 \\
\hline$+\mathrm{R} 122 \mathrm{H}$ & $M$ & 48,50 & 26,2 & 24 \\
\hline$+\mathrm{R} 122 \mathrm{H}$ & $M$ & 51,54 & 7,25 & 18 \\
\hline$+\mathrm{R} 122 \mathrm{H}$ & M & 58,58 & 5,12 & 7 \\
\hline$+\mathrm{N} 29 \mathrm{I}$ & $\mathrm{F}$ & 33,37 & 2,13 & 11 \\
\hline$+\mathrm{N} 29 \mathrm{I}$ & $\mathrm{F}$ & 42,44 & 6,28 & 22 \\
\hline + N29I & $\mathrm{F}$ & 49,53 & 41,6 & 35 \\
\hline
\end{tabular}


and mean (SD) intervals between age of disease onset were $2(1,6)$ and 6 (9), respectively.

The comparison group included 33 pairs of mutation, sex, and age matched $\mathrm{R} 122 \mathrm{H}$ (30 pairs) and N29I (three pairs) subjects (table 3). The median (Q1, Q3) and mean (SD) differences in the age of disease onset for individuals with a known mutation were $7(2,15)$ and 11.7 (14.3) years, respectively.

Thus among concordant twins there was a similar age of disease onset with the affected sibling pair group $(p=0.096)$ and a significantly shorter interval in the age of disease onset than mutation, sex, and age matched pairs $(p=0.0115)$. These results support the hypothesis that monozygotic twins within similar environments would develop the typical signs of $\mathrm{HP}$ at a similar age.

PHENOTYPICALLY DISCORDANT TWIN PAIRS The pedigrees of the $A$ and $G$ kindreds are presented in fig 1 . The A kindred twins (A1:A2) were females aged 41 years at interview. Testing of informative microsatellite markers from 10 different chromosomes

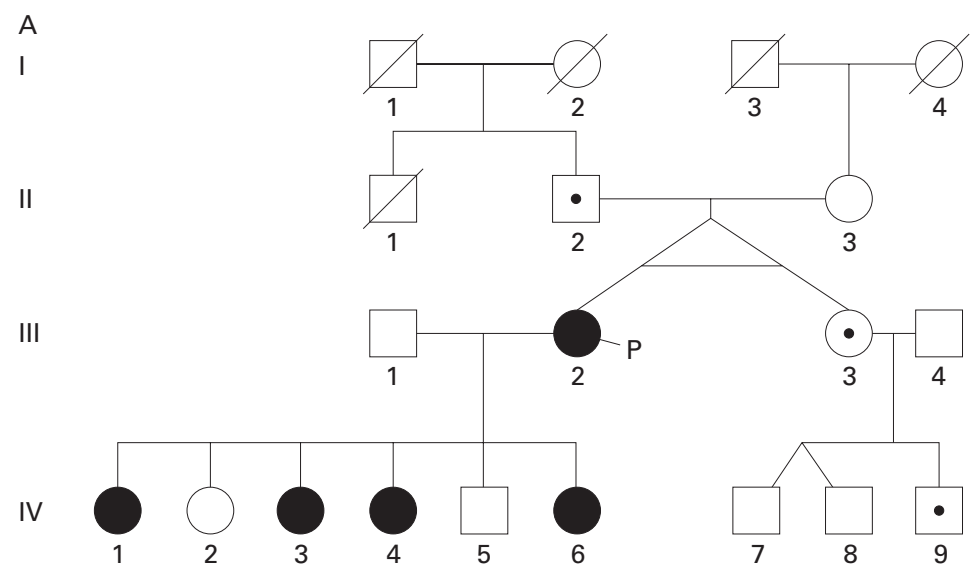

B

।
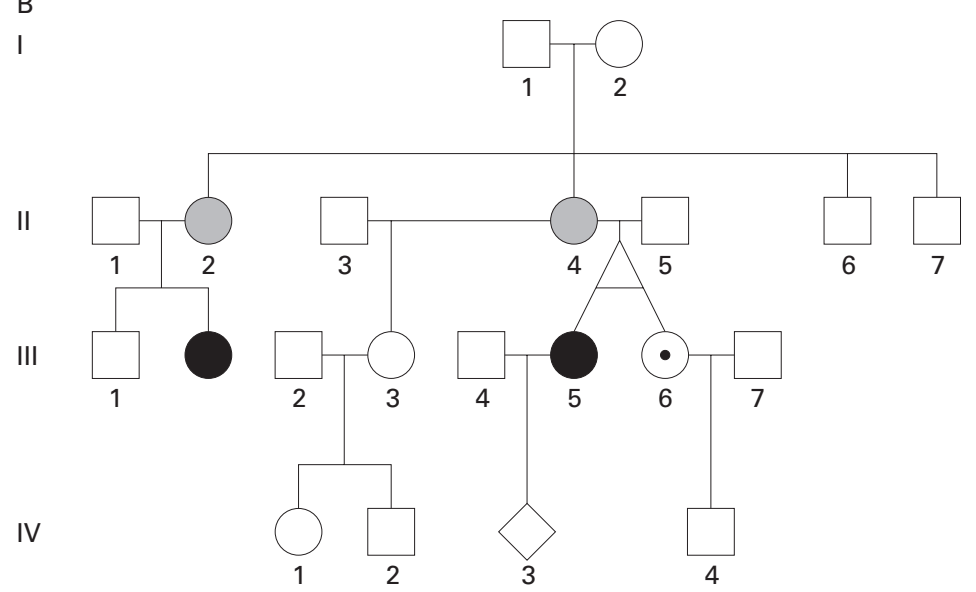

Suspected pancreatic $\bullet$ Gene positive disease

Gene positive and phenotype

Figure 1 A and B represent kindreds " $A$ " and " $G$ ", respectively. In both of these families the twins were raised in the same environment, attended the same college, and lived together until their 20s. Despite identical genes and very similar environments, only one twin of each pair developed phenotypic hereditary pancreatitis. proved monozygosity. Their birth weights were 5 pounds 13 ounces (A1) and 4 pounds 5 ounces (A2). Their environments were similar. They were raised together in the same household and attended the same college where they continued to room together. Neither twin reported a significant history of tobacco or alcohol use, illnesses (except for pancreatitis related problems), infections, stress, or trauma. The affected sibling (A1) developed symptoms of pancreatitis at age five. The diagnosis of chronic pancreatitis was confirmed at age 15 by a histological examination of a pancreatic biopsy taken during surgery for complications of acute and chronic pancreatitis. The other sibling (A2) remained symptom free at age 41 years.

The $\mathrm{G}$ kindred twins (G1:G2) were females aged 36 years at interview. Testing of informative microsatellite markers from eight different chromosomes proved monozygosity. Their birth weights were 3 pounds 13 ounces (G1) and 3 pounds 15 ounces (G2). They were raised within the same household, had similar interests and hobbies, denied a significant history of tobacco or alcohol use, illness (except for pancreatitis related problems), infection, stress, or trauma. They also attended the same college. The affected sibling (G1) had onset of symptoms at age 13 and computed tomography scan confirmed chronic pancreatitis at age 26 . The other sibling (G2) remained symptom free at age 36 years.

The V twins (V1: V2) are from the Virginia kindred originally reported by Kattwinkle and colleagues $^{12}$ and were found to have the cationic trypsinogen R122H mutation by Pandya and colleagues. ${ }^{21}$ Although these male twins were unavailable for formal evaluation, the phenotypically unaffected twin (V2) had two children with HP with an age of onset in their late teens. The phenotypically positive twin (V1) had no natural children. Thus it is nearly certain that both the affected and unaffected twin carried the cationic trypsinogen $\mathrm{R} 122 \mathrm{H}$ mutation but were discordant for phenotypic expression of the disease. Both twins are deceased and were not available for monozygosity testing.

When all of the twins are considered together, 11 of the 14 individuals at risk of developing pancreatitis had phenotypic expression of the disease. Thus the penetrance of the pancreatitis phenotype in monozygotic twins was $78.6 \%$. This rate is similar to the $80 \%$ penetrance rate seen in large family studies. However, because the phenotypic expression was discordant in three of the twin pairs, the hypothesis that penetrance is exclusively due to polymorphisms in modifier genes or environment could not be supported.

\section{Discussion}

Since the original recognition of $\mathrm{HP}$ as a distinct disease in $1952,{ }^{1}$ more than 200 additional families have been identified. ${ }^{13} 1622$ Several exceptionally large kindreds ${ }^{13}{ }^{17} 2123$ facilitated the rapid identification of the genetic mutations in the cationic trypsinogen gene associated with $\mathrm{HP}^{67132123}$ The $\mathrm{R} 122 \mathrm{H}$ and 
N29I mutations first identified by Whitcomb and colleagues have now been confirmed in families throughout the USA, Europe, and Japan. ${ }^{64-27}$ Additional mutations are also likely as a disease gene locus on chromosome 7 q35 has now been excluded in multiple families. ${ }^{9} 10$

One striking feature of the large HP kindreds is the variability in age of onset but consistency in penetrance rate at $80 \% .^{2{ }^{311-13}}$ We therefore speculated that these observations may reflect the influences of genetic and environmental factors.

Twin studies offer a powerful tool to study and differentiate the effects of genetic factors from other environmental influences on phenotype expression. We hypothesised that environmental factors and modifier genes would increase the concordance rate of monozygotic twins in comparison with sib pairs or more remotely related family members and unrelated affected individuals with the same mutation. In the present study, the age of phenotypic onset in concordant twins was strikingly similar. Phenotypic onset in sibling pairs, with assumed similar environments and a difference of about $50 \%$ of the modifying genes, had a difference in age of onset close to that of monozygotic twins. The difference in age of onset was significantly larger in mutation, sex, and age matched controls compared with monozygotic twins. These results confirm the importance of genetics and environmental factors in determining the age of symptomatic onset. However, we also observed incomplete penetrance of $\sim 80 \%$ in the twin sets. This is consistent with the worldwide penetrance of $80 \%$, despite the worldwide population having significant genetic and environmental variability.

Three affected twin pairs, (A, G, and V) were phenotypically discordant. At least two of these discordant twins (A and $G$ ) were raised together, sharing a common environment. However, in each case one of the twins suffered from moderate to severe HP while the other remained symptom free. In each case, sufficient time had elapsed for typical clinical features of HP to be expressed in the unaffected twin. At the age of 41 and 36 years, the twins are well beyond the typical age of onset of HP. ${ }^{2} 131622$ In twin and family studies, environmental factors are typically divided into shared or common environmental factors that are experienced by all members of a nuclear family and random events that affect individuals regardless of the social or genetic relationship. Our evidence suggests that the effects of modifier genes and common environmental influences are important factors but random events play a role in the expression of the pancreatitis phenotype. If these factors could be identified, they might suggest effective therapeutic interventions.

There are a few possible explanations for discordant phenotypes. One possibility is genetic imprinting. Imprinting is an epigenetic modification of DNA involving the allele specific methylation of genomic DNA resulting in differential gene expression. ${ }^{27}{ }^{28}$ Persistent methylation of the affected allele in obligate carriers could explain this observation. The earliest methylation dependent changes in gene expression were recognised in parent of origin diseases such as Prader-Willi syndrome, Angelman syndrome, and the Beckwith-Weidemann syndrome. ${ }^{29}$ However, more complex patterns of methylation-demethylation-remethylation may be equally or more important. ${ }^{27} 28$ Since waves of de novo methylation may establish new methylation patterns during both gametogenesis and early post implantation development, ${ }^{28}$ a mechanism exists for organ specific affected allele methylation in the discordant $\mathrm{R} 122 \mathrm{H}$ and N29I trypsinogen family twins and non-penetrant carriers. Another possibility is the effects of mitochondrial DNA; monozygotic twins do not necessarily share the same population of mitochondria. Although the explanations remain speculative, it is clear that non-penetrance represents an important epigenetic phenomenon requiring further investigation.

In summary, $\mathrm{HP}$ is a disease with variable severity and age of onset with a worldwide penetrance of $80 \%$. Although the majority of monozygotic twins from HP kindreds are concordant for disease phenotype and show a remarkably similar age of onset, at least three clear cases of non-penetrance of HP in monozygotic twins have been identified. These observations indicate that inherited modifier genes or shared environmental factors cannot be the only determinants of penetrance. Understanding the mechanism of nonpenetrance and phenotype expression in HP would be an important step in understanding the clinical expression of this disease and may provide a key to new therapies that would minimise expression of HP in patients born with a genetic predisposition to the disease.

We appreciate the technical assistance of Suzanne Applebaum Shapiro, Paul Wood, and Mike Ford. Supported in part by: NIH-DK51954 (DCW), NIH AA10885 (DCW), NIH DK51954 (DCW), VA Merit Review (DCW), and the Center for Genomic Sciences, University of Pittsburgh. Portions of this Hereditary Pancreatitis, Cincinnati, Ohio, March 1999.

1 Comfort M, Steinberg A. Pedigree of a family with hereditary chronic relapsing pancreatitis. Gastroenterology 1952;21:54-63

2 Sossenheimer MJ, Aston C, Ehrlich GD, et al. Clinical characteristics of hereditary pancreatitis in a large family based on high-risk haplotype. Am $\mathcal{F}$ Gastroenterol 1997;92: 1113-16.

3 Sibert JR. Hereditary pancreatitis in England and Wales. $\mathcal{F}$ Med Genet 1978;15:189-201.

4 Antonarakis SE and the Nomenclature Working Group. Recommendations for a nomenclature system for human gene mutations. Hum Mutat 1998;11:1-3.

5 Whitcomb DC. Hum Mutat 1998;1:1-3. chronic pancreatitis. Med Clin North Am 2000;84:531-47.

6 Whitcomb DC, Gorry MC, Preston RA, et al. Hereditary pancreatitis is caused by a mutation in the cationic pancreatitis is caused by a mutation in
trypsinogen gene. Nat Genet 1996;14:141-5.

7 Gorry MC, Gabbaizadeh D, Furey W, et al. Multiple mutations $\mathrm{MC}$, Gabbaizadeh D, Furey W, et al. Multiple muta-
tions cationic trypsinogen gene are associated with hereditary pancreatitis. Gastroenterology 1997;113:1063-8.

8 Witt H, Luck W, Becker M. A signal peptide cleavage site mutation in the cationic trypsinogen gene is strongly associated with chronic pancreatitis. Gastroenterology 1999; 117:7-10

9 Dasouki MJ, Cogan J, Summar ML, et al. Heterogeneity in hereditary pancreatitis. Am f Med Genet 1998;77:47-53.

10 Bartness MA, Duerr RH, Ford MA et al. A new hereditary pancreatitis gene may map to chromosome 12. Pancreas 1998;17:426

11 Gabbaizadeh D, Gates Jr LK, Ulrich II CD, et al. Clinical features of hereditary pancreatitis in a family with a new genotype. Gastroenterology 1997;112:A442.

12 Kattwinkel J, Lapey A, Di Sant'Agnese PA, et al. Hereditary pancreatitis: three new kindreds and a critical review of the pancreatitis: three new kindreds and

13 Le Bodic L, Schnee M, Georgelin T, et al. An exceptional genealogy for hereditary chronic pancreatitis. Dig Dis Sci 1996;41:1504-10. 
14 Mathew P, Wyllie R, Van Lente $\mathrm{F}$, et al. Antioxidants in hereditary pancreatitis. Am f Gastroenterol 1996;91:155862 .

15 Segal I, Gut A, Schofield D, et al. Micronutrient antioxidant status in black South Africans with chronic pancreatitis: opportunity for prophylaxis. Clin Chim Acta 1995;239:71-9.

16 Perrault J. Hereditary pancreatitis. Gastroenterol Clin N Am 1994;23:743-52.

17 Whitcomb DC, Preston RA, Aston CE, et al. A gene for hereditary pancreatitis maps to chromosome $7 \mathrm{q} 35$. Gastroenterology 1996;110:1975-80.

18 Beall JH, Bell JW, Jesseph JE, et al. Fatal acute hemorrhagic pancreatitis occurring simultaneously in identical twins. Gastroenterology 1960;39:215-18.

19 Freud E, Barak R, Ziv N, et al. Familial chronic recurrent pancreatitis in identical twins. Case report and review of the literature. Arch Surg 1992;127:1125-8.

20 Henderson J, Ingram D, House T. Acute pancreatitis in identical twins. Med f A A ust 1982;1:432-4.

21 Pandya A, Blanton SH, Landa B, et al. Linkage studies in a large kindred with hereditary pancreatitis confirms mapping of the gene to a $16-\mathrm{cm}$ region on $7 \mathrm{q}$. Genomics 1996 ; ping of the

22 Madraso-de la Garza J, Hill I, Lebenthal E. Hereditary pancreatitis. In: Go VLW, Di Magno EP, Gardner JD, et al, eds.
The pancreas: biology, pathophysiology, and disease, 2nd edn. New York: Raven Press, 1993:1095-101.

23 Le Bodic L, Bignon JD, Raguenes O, et al. The hereditary pancreatitis gene maps to long arm of chromosome 7. Hum Mol Genet 1996;5:549-54.

24 Gress TM, Micha AE, Lacher U, et al. Diagnosis of a "hereditary pancreatitis" by the detection of a mutation in the cationic trypsinogen gene (in German). Dtsche Med Wochenschr 1998;123:453-6.

25 Teich N, Mossner J, Keim V. Mutations of the cationic trypsinogen in hereditary pancreatitis. Hum Mutat 1998; 12:39-43.

26 Nishimori I, Kamakura M, Fujikawa-Adachi K, et al. Mutations in exon 2 and 3 of the cationic trypsinogen gene in Japanese families with hereditary pancreatitis. Gut 1999;44: 259-63.

27 Turker MS, Bestor TH. Formation of methylation patterns in the mammalian genome (review). Mutat Res 1997;386: 119-30.

28 Yoder JA, Bestor TH. Genetic analysis of genomic methylation patterns in plants and mammals (review). Biol Chem tion patterns in plant

29 Lalande M. Parental imprinting and human disease (review). Anпu Rev Genet 1996;30:173-95. 